\title{
Rhabdomyosarcoma of Parotid Gland
}

\author{
Arun Goel, Senior Resident, Dept. of E.N.T., S. C. Gupta, Head, Dept. of E.N.T., \\ S. C. Gupta, Head, Dept. of Pathology, D. N. Awasthi, Head, Dept. of Radiotherapy, \\ M. L. N. Medical College, Allahabad-211001.
}

A rare case of rhabdomyosarcoma of parotid gland in a child is being reported along with a brief review on its incidence, presentation, management and prochosis.

\section{INTRODUCTION}

Rhabdomyosarcoma (RMS) is the most common variety of soft tissue sarcoma in childhood. This tumour has a predilection for certain areas including the head and neck, the extremities and the genitourinary tract.

The primary sites of childhood head and neck soft tissue sacroma may be divided into three groups - the orbit and eye group is most frequent single primary site and is distinguished by high cure artes. Second group consists of parameningeal sites which include infratemporal fossa, middle ear, nasopharynx, nasal cavity and paransal sinuses. The remaining group including parotid region comprises of about onefourth of head and neck sarcomas (Wharam Jr. et al, 1984).

Major salivary gland tumours in children are uncommonly and infrequently diagnosed (Castro et al, 1972) Primary sarcoma of the salivary glands are seldomly seen in children. Proops et al (1984) studied 22 children with histologically confirmed rhabdomyosarcoma of head and neck but could not find even a single case of rhabdomyosarcoma arising from parotid tissue. Krolls et al (1972) found only 5 cases of rhabdomyosarcoma among 168 cases of salivary gland neoplasm from paediatric age group.

Castro et al (1972) did not find any sarcoma arising from major salivary glands among 38 tumours in paediatric age group. Luna et al (1991) stressed that several features distinguish the salivary neoplasms in paediatric age group as compared to those in adults -1) A much greater frequency of non-epithelial tumours, 2) a higher proportion of malignant neoplasms when nonepithelial tumours are excluded and 3) a preponderence of parotid gland involvement.

Because of its rarity a case of rhabdomyosarcoma arising from parotid gland is being reported here.

\section{CASE REPORT}

A 10 yrs. old female child was admitted to our hospital on 9th Aug. 1992 with the chief complaints of a progressively enlarging, swelling of a 4 months duration in front of right ear. She also complained of occasional sharp pain in right ear from same duration. There was no history of fever or any other constitutional symptoms.

On general examination the child was afebrile but anaemic. On local examination there was a smooth, well-circumscribed swelling of about 6 $x 6 \mathrm{~cm}$ in size in the left parotid region (Fig 1A \& $B)$. The colour of overlying skin was normal. Lower part of pinna was pushed outward. On palpation the swelling was hard, non-tender and fixed to the deeper structures. The temperature of overlying skin was normal but skin was adherent to the swelling. The external auditory canal was narrowed but there was no mass in the ear.

Facial nerve was intact and there was no trismus. An upper deep cervical group of lymph node on the same side was palpabale, hard, fixed and nontender. 


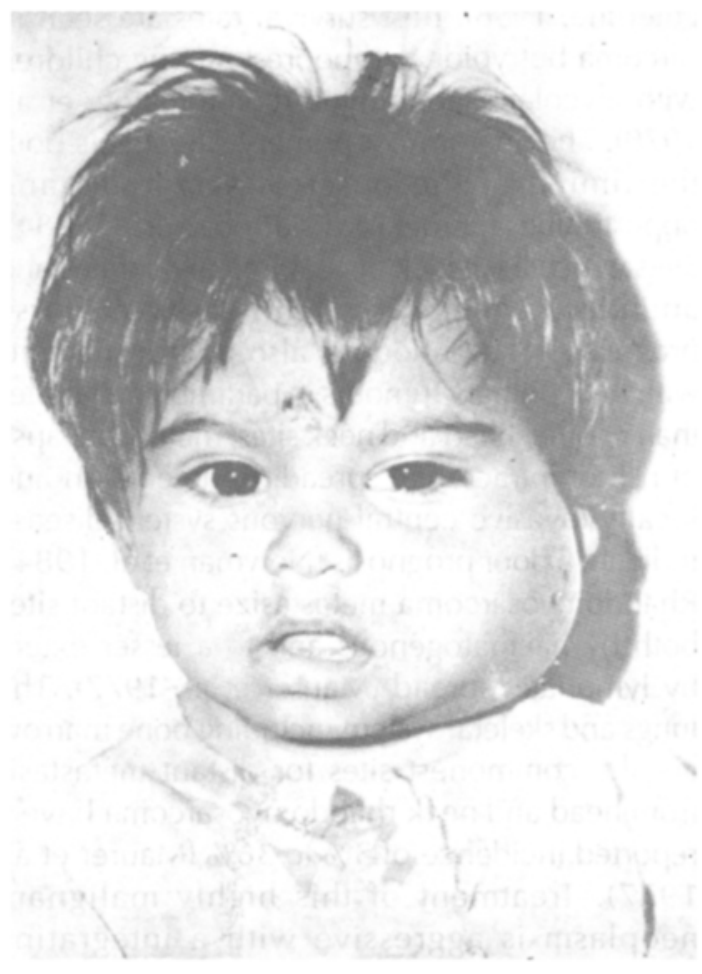

Fig-1A

Showing a smooth well-circumscribed swelling in the left parotid region

Report of FNAC was inconclusive so an open biopsy was performed. Histopathology report revealed pleomorphic rhabdomyosarcoma. Neoplasm encapsulated in fibrous tissue was compressed by parotid gland tissue. The original tumour was composed primarily of relatively uniform, interlacing bundles of plump spindle cells with vesicular nuclei. Occasionally roundert multinucleated giant cells with acidophillic granular cytoplasm was also seen. At places typical tadpole like cells were present. Special stainly with P.T.A.H. (Phosphotungestic acid haematoxylin stain) showed presence of myofibrils in these cells confirming diagnosis of rhabdomyosarcoma (Fig.2).

Patient was kept in group-III of clinical staging of rhabdomyosarcoma as classified under Intergroup Rhabdomyosarcoma Study (Maurer et al 1977). A treatment protocol of combination of radiotherapy and chemotherapy was planned but her general condition deteriorated and she

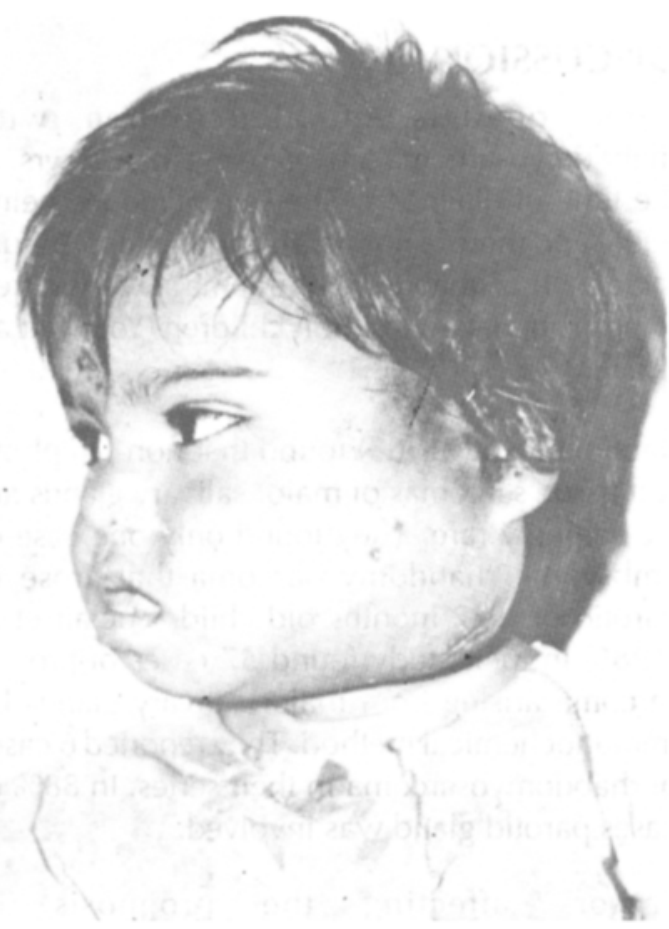

Fig-1B

Showing a smooth well-circumscribed swelling in the left parotid region

died after receiving 2 doses of chemotherapy consisting of cyclophosphamide $1500 \mathrm{mg} / \mathrm{m}^{2} \mathrm{i} / \mathrm{v}$ puch dav 1), vincrictine $11 \mathrm{mo} / \mathrm{m}^{-i}$ 'v push dav 1

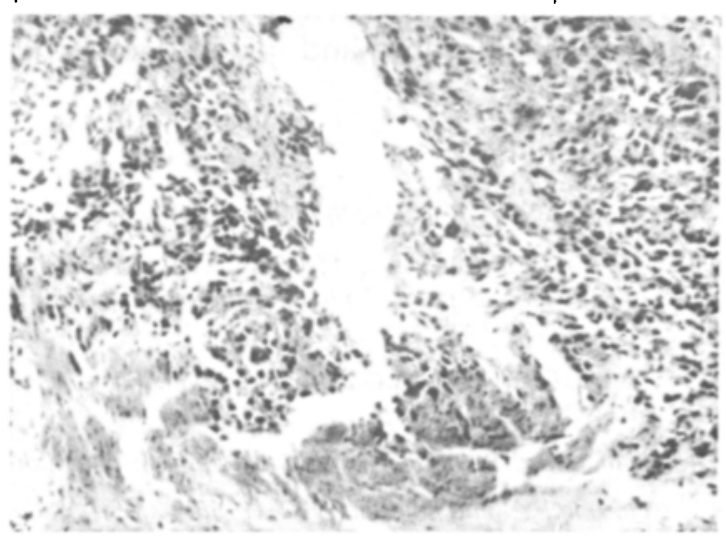

Fig-2

Histopathology of Rhabdomyosarcoma : Showing plump spindle cells with vesicular nuclei $(H \& E \times 100)$. 
and 5$)$, adriamycin $\left(20 \mathrm{mg} / \mathrm{m}^{2} \mathrm{i} / \mathrm{v}\right.$ day 1$)$ and dactinomycin ( $250 \mathrm{mg} / \mathrm{m}^{2} \mathrm{i} / \mathrm{v}$ push day 1 to 5 ) at interval of 3 to 4 weeks.

\section{DISCUSSION}

Three quarters of all children with rhabdomyosarcoma are aged less than $10 \mathrm{yrs}$. at the time of diagnosis. The sex incidence being equal and there is no racial predilection. Annual incidence of rhabdomyosarcoma is considered to be around 4 per million children (Young et al, 1975).

Kauffman et al (1963) found that non-lymphoid soft tissue sarcomas of major salivary glands are exceedingly rare. They found only one case of embryonal rhabdomyosarcoma that arose in parotid of a 22 months old child. Auclair et al (1986) in their study found 57 cases of proved sarcoma arising from major salivary glands by immunochemical method. They reported 6 cases of rhabdomyosarcoma in their series. In $88 \%$ of cases parotid gland was involved.

Factors affecting the prognosis of rhabdomyosarcoma in children are age, histology, primary site, extent of disease and treatment (Sutow et al, 1970; Proops et al 1984). Patients who present when aged under 2 yrs. tend to have less advanced disease (Maurer et al, 1977). Rhabdomyosarcoma has been classified into four pathological categories embryonal, alveolar, pleomorphic and mixed (Horn and
Enterline, 1958). Best survival rates are seen in sarcoma botryoids and poorest among children with alveolar rhabdomyosarcoma (Sutow et al, 1970). The anatomy of primary site affects both the timing of the onset of symptoms and opportunities for metastasis (Proops et al, 1984). Sites which have lack of anatomical confines and abundant lymphatics, tend to have worse prognosis. The outlook is also poor in patients with their primary tumours in parameningeal sites than in other head and neck sites, mainly because of risk of intracranial spread. Bone erosion and locally invasive central nervous system disease indicate a poor prognosis (Newman et al, 1984). Rhabdomyosarcoma metastasize to distant sites both by haematogenous and to a lesser extent by lymphatic spread (Maurer et al, 1977). The lungs and skeletal system including bone marrow are the commonest sites for distant metastasis from head and neck rhabdomyosarcoma have a reported incidence of $3 \%$ to $36 \%$ (Maurer et al, 1977). Treatment of this highly malignant neoplasm is aggressive with a integrating approach utilising surgery, radiation therapy and chemotherapy (Jenkins et al, 1980). The head and neck anatomical complexity and resultant functional and cosmetic deformity do not justify such radical approach. Intergroup rhabdomyosarcoma study report has recommended radiotherapy between 5000-6000 rads in 5 to 6 weeks to primary tumour, given synchronously with chemotherapy (Maurer et al, 1977).

\section{References}

1. Anderson and Byars (1965): Surgery of the parotid gland. Saint Louis : The C. V. Mosby Company.

2. Auclair, P.L., Langlass, J.M., Weiss, S.W. and Corio, R.L. (1986) : Sarcomas and sarcomatoid neoplasms of the major salivary gland regions-A clinicopathological and immuno-histochemical study of 67 cases and review of the literature. Cancer, 58 ; 1305-1315.

3. Castro, E.B., Huvos, A. G., Strong, E.Q. and Foote, F.W. (1972): Tumours in major salivary glands in children. Cancer, 29 :312-317.

4. Galich, R. (1969) : Salivary gland neoplasms in children, archives of Otolaryngology, $89: 878-882$.

5. Horn Jr. R.C. and Enterline, H.T. (1958): RMS - A clinicopathological study and classification of 39 cases. Cancer, 11 : 181-199.

6. Jenkin, R.D. and Sonley, M. (1980) : Soft tissue sarcoma in young, medical treatment advances in perspective. Cancer, $46: 621-625$. 
7. Kauffman, S.L. and Stout, A.P. (1963): Tumours in major salivary glands in children. Cancer, $16: 1317-1331$.

8. Krolls, S. G., Trodahl, N.J. and Boyers, R.C. (1972) : Salivary gland lesions in children : a survey of 430 cases. Cancer, 30 :459-469.

9. Lawrence Jr. W. Hays, D.M. and Moon, T.E. (For IRS committee) (1977) : Lymphatic metastasis with childhood rhabdomyosarcoma. Cancer, $39: 556-559$.

10. Luna, M.A.; Batskin, J.G. and EL Naggar, A.K. (1991): Pathology consultation - Salivary gland tumours in children. Annals of Otology, Rhinology and Laryngology: 869-871.

11. Marsden, H.B. and Steward, J.K. (1976) : Tumours in children. Springer - Verlog, Berlin, Heidelberg, New York 2nd edition : 282-301.

12. Maurer, H.M.; Moon T., Donaldson M.; Fernandez, G.; Gehan, E.A.; Hemond, D.; Hays D.M.; Lawrence Jr. W.; Newton, W.; Ragab, A., Raney, B.; Saule, E.H.; Sutow, W.W. and Tefft. M. (1977) : - The intergroup rhabdomyosarcoma study: a preliminary report. Cancer, $40: 2015-2026$.

13. Newman, A.N.; Rice, D.H. and Angles, L. (1984): Rhabdomyosarcoma of the head and neck. Laryngoscope, $94: 234-$ 239.

14. Proops, D.W. and Mann, J.R. (1984): The presentation of rhabdomyosarcoma of the head and neck in children. Journal of Laryngology and Otology, $98: 381-390$.

15. Sutow, W.W.; Sullivan, M.P.; Ried, H.L.; Tayler, H.G. and Griffith, K.M. (1970) : Prognosis in childhood rhabdomyosarcoma. Cancer, $25: 1384-1390$.

16. Teff, M.; Fernandez, C.; Donaldson, M.; Newton, W. and Moon T.E. (1978) : Incidence of meningeal involvement by rhabdomyosarcoma of the head and neck in children. A report of the intergroup rhabdomyosarcoma study (IRS). Cancer, $42: 253-258$.

17. Wharam, Jr. M.D.; Foilkes, M.A.; Lawrence Jr., W.; Lindberg, R.D.; Maurer, H.M.; Newton, W.A.; Ragab, A.H.; Raney, R.B. and Teff, M. (1984) : Soft tissue sarcoma of head and neck in children : Non-orbital and non-meningeal sites. A report of the intergroup rhabdomyosarcoma study (IRS). Cancer, $53: 1016-1019$.

18. Young, J.L. and Miller, R.W. (1976) : Incidence of malignant tumours in U.S. children. Journal of Paediatrics, 86 : 254-258. 